\title{
On the Design of a Parallel Algorithm for VLSI Layout Compaction
}

\author{
K. Thulasiraman, M.A. Comeau, R.P. Chalasani, A. Das
}

Dept. of Electrical and Computer Engineering

and

J.W. Atwood

Dept. of Computer Sclence

Concordla University

1455 de Malsonneuve W. Montreal, Canada

$\mathrm{H} 3 \mathrm{G} 1 \mathrm{M} 8$

\begin{abstract}
$\underline{A B S T R A C T}$
In this paper we present the essentlal features of an approach for the design of a parallel algorlthm for the layout compaction problem. We begin with a formulation of the problem presented by Yoshimura in [4]. This formulation is in terms of the dual transshlpment problem. Our approach to the solution of the dual transshipment problem involves repeated applications of three basic steps, namely, testing feasibility, shortest-path computatlons and performing concurrent plvot operations. Our discussion is in terms of marked graph concepts and results presented in $[5],[6]$. Our approach can also be used in the study of the relative placement problem discussed in [7] by Mlynski and Welss.
\end{abstract}

\section{INTRODUCTION}

VLSI designers have come to rely heavlly on automatic layout tools. Therefore it has become necessary that these tools have the ability to do a good job minimizing the flnal area and other costcritical factors. But better quality comes at the price of much longer computation tlme. One way to alleviate this problem is to take advantage of fast commercially avallable parallel computers. Thus for different steps in the layout phase of the VLSI design process, parallel algorithms whlch are sultable for implementation on a MIMD multiprocessor and which result in conslderable savings in computing time are called for. Recent work on the design of multiprocessor based algorithms for certain phases of the layout problem may be found in [1]. [2], [3].

In this paper, we are concerned with the design of a parallel algorlthm for the layout compaction problem. The paper is organlzed as follows. In Section II, we present a brief revlew of literature on the compaction problem. We also present the work of Yoshimura [4] whereln he formulates the problem as a dual transshipment problem. The remainder of the paper is concerned with our research towards design of distributed and parallel algorithms for the dual transshlpment problem. Our approach is based on results and concepts from the theory of marked graphs presented in [5], [6].

\section{LAYOUT COMPACTION}

Compaction is the $\mathrm{CAD}$ tool used to pack rough sketches or symbolle diagrams to produce IC layouts. Manual compaction is tedlous, timeconsuming, and error-prone; automated compaction tools can greatly shorten the layout deslgn cy- cle. The alm of layout compaction can be stated as follows: Starting from an initial layout and without changing 1ts topology, a flnal mask layout has to be achleved with a minimum chip area and consistent with design rules. The restriction to invariance of topology is necessary in order not to render the prevlous steps of placement and routing obsolete. It is achleved by maintalning relative nelghbors, l.e. adjacency of layout elements. Elements are elther on the bottom-most mask level, e.g. diffusion windows, or on higher design levels, e.g. translstors and cells. These elements are not allowed to Jump across each other during compaction.

Most of the avallable compactors are based on some one-dimenslonal approach which solves the two-dimensional compaction problem by two one-dimensional procedures, 1.e. a horlzontal compaction and a vertical compaction. These two procedures are applied successlvely. Thus, the layout elements are moved in one direction at a time changing either thelr $\mathrm{x}$-coordlnates only during horizontal compaction or thelr $y$-coordinates only during vertical compaction.

A simultaneous compaction in both the horizontal and the vertical directions is preferable, since it avolds the tradeoff of moving an element in elther direction. Although a general twodimensional compaction strategy is not yet avallable, all attempts to treat $\mathrm{x}$ - and $\mathrm{y}$ - positions slmultaneously at least during some part of the compaction procedure shall be classifled as twodimensional approach.

In our work, we will be primarlly concerned with the one-dimenstonal approach. Of the several strategles based on the one-dimensional method, the constralnt graph approach seems to be most promising from the point of view of parallel implementation. This approach consists of two main steps: (1) bulld the constraint graph to indicate the relative positions and the minimum distance required among the elements, (2) solve the constraint graph to minimize the chip area using the longest path method. The baslc constraint-graph approach separates the compaction problem into two independent compactlons, one in the $X$ direction and the one in the Y-direction. During $\mathrm{X}$-compaction, elements can only move strictly horizontally to the left, and during Y-direction elements can only move strictly vertically to the bot- 
tom. Simultaneous compaction in both directions have been considered in the literature. In addition to compressing spaces, the compaction process may expand the input to resolve design-rule vlolations. The user can do as many $\mathrm{X}$ - and Y-compactions as necessary. To satisfy all spacing constraints, each node element must be at least its longest path's length away from the boundary element, but it does not need to exceed that distance. Hence, a solution of the maximum-packing problem is that each node should be at that distance, assuming the boundary element is located at $x=0$. Since all spacing constralnts are satisfled by this solution, X-compaction also corrects design-rule violatlons In the X-direction that may have been in the vlolations. Overall, the constralnt-graph model offers better flexibllity than the other models and stlll allows for efflcient implementation.

Our work on parallel algorithm design will start with a formulation of Yoshimura [4] described below.

Given : Initlal placement of blocks, horizontal wire segments and vertical wire segments,

Subject to: Reservation of the relative positions between blocks and horizontal wire segments. No overlaps between blocks and wire segments.

Minimize: Chip helght and total wire length in Y-direction.

First a directed graph $\mathrm{G}(\mathrm{V}, \mathrm{E})$ is constructed, where $\mathrm{V}$ and $\mathrm{E}$ are the node set and the edge set, respectlvely. Each node corresponds to a block upper edge, a block lower edge or a horizontal wire segment. Using this graph, a minimum helght layout can be obtalned by calculating a "constrained longest dlstance tree".

The total wire length minimization problem is formulated as a linear programming problem. The constralnts are described as follows: $u_{i}-u_{j}>d_{i j}$ where $u_{i}$ and $u_{j}$ are y-coordinates for nodes $i$ and node $j$, respectlvely and $d_{i j}$ is a constant. An optimum solution is constructed using a varlation of the simplex method.

It can be seen that the above formulation of the compaction problem is in terms of the dual transshipment problem. We also note that Mlynskl and Welss [7] formulate the relative placement problem in terms of the dual transshipment problem. Thus the approach we shall be presenting in the following sections will also be appllcable in the study of the relatlve placement problem. For a good treatment of standard algorithms for network optimlzation problems, [8] may be referred.

\section{Dual Transshipment Problem: A New Approach}

Glven a marked graph $\mathrm{G}=(\mathrm{V}, \mathrm{E})$ on $n$ nodes and $m$ edges, with the token vector $M_{0}$ associated with the edge set $\mathrm{E}$, let $\mathrm{A}$ denote the Incldence matrix of G. Then the dual transshipment problem is a linear program deflned as follows:

$$
\begin{gathered}
\text { minimize WY } \\
\text { subject to } A^{t} Y \geq-M_{0} \\
Y \geq 0
\end{gathered}
$$

where $\mathrm{Y}$ is a column vector of dimension $\mathrm{n}$ and $\mathrm{W}$ is a row vector also of dimension $n$. Vectors $W$ and $M_{0}$ are specifled. $M_{0}$ is called a marking of $\mathrm{G}$ and the elements of $M_{0}^{0}$ are called tokens. Note that unllke in traditional marked graphs, we do not restrict tokens to non-negative integers.

$A$ vector $Y \geq 0$ which satisfles (1) is called a feasible solution of the dual transshipment problem. If such a vector exists, then the given dual transshipment problem is feasible. So, the flrst step in the solution of the dual transshlpment problem is to test the feasibility of the problem. We now present an algorithm for this problem. In the following, the token of a directed path is given by the sum of the tokens of the edges on the path. Similarly a token of a directed circuit is deflned.

\section{Theorem 1:}

The dual transshipment problem is feasible if and only if the marked graph $G$ has no directed clrcuit of negative token. //

Let $d_{i j}$ denote the token of a minimumtoken directed path from node $i$ to node $j$. Let

$$
\gamma_{i}=\max \left\{0,-\min _{j}\left\{d_{i j}\right\}\right\}, i=1,2, \ldots, n(3)
$$

\section{Theorem 2:}

The vector $\mathrm{Y}=\left(\gamma_{1}, \gamma_{2}, \ldots, \gamma_{n}\right)^{t}$ is a feasible solution of the dual transshipment problem if the marked graph $G$ has no directed clrcult of negative token. // $[9]$.

Proof of the above theorems may be found in

To present an algorithm which obtains the feasible solution given in the above theorem, let us define the node firing operation as follows. Firing $x$ times a node $v$ refers to the operation of adding $x$ to the token of every outgoing edge at $v$ and subtracting $x$ from the token of every incoming edge at $v$. In the following, $M(\mathrm{e})$ denotes the token of edge $e$. Firing number of a node refers to the number of times the node has been flred. To start with all the firing numbers are zero. Note that in our algorithm the value of $y_{i}$ at any time will in fact be equal to the firing number of the node at that time. 
Algorithm FEASIBLE:

1 Let $\mathrm{M}=\mathrm{M}_{0}$

2 While there exists an edge $e=(i, j)$ such that $\mathrm{M}(\mathrm{e})<0$, flre node $i$, $-\mathrm{M}(\mathrm{e})$ times, updating M.

\section{Theorem 3:}

If the marked graph has no negatlve token directed circults under the token vector $M_{O}$, then algorithm FEASIBLE terminates in a finite number of steps after firing each node $i$ exactly $\gamma_{i}$ tlmes.

Proof of correctness and termination of this algorithm may be found in [9].

We next present an implementation of the above algorithm which achleves a tlme complexity of $\mathrm{O}(\mathrm{mn})$. The maln steps in this implementation are:

Step 1: For each $i$, set $\gamma_{i}=0$. Let $M_{0}$ be the Initial token vector assoclated with the edge set.

Step 2: For each $i$, compute $\sigma_{i}=\max \{0$, $\left.-\min _{j}\{\mathrm{M}(\mathrm{i}, \mathrm{J})\}\right\}$

Step 3: Fire each node $i, \sigma_{i}$ times and update $\gamma_{j}$ by adding $\sigma_{i}$ to its current value (Note that firing results in updating $M$ also).

Step 4: If $\sigma_{i}$ for all $i$, STOP. ELSE return to Step 2.

A distributed/parallel Implementation of the above algorithm which achieves a time complexity of $\mathrm{O}(\mathrm{n})$ and message complexity of $\mathrm{O}(\mathrm{mn})$ is glven in [9], In this implementation each node is assoclated with a single processor and information is communlcated from one processor to another through messages.

Suppose that the given dual transshipment problem is feasible. Then, after an appllcation of Algorlthm FEASIBLE, all the tokens assoclated with the edges will be non-negative. Let the corresponding graph be $G^{\prime}$. From this point onwards, our approach is to decrease the value of the objective WY as much as possible untll optimality is reached. This is achleved by firing the nodes in an appropriate manner without ever allowing the tokens to become negative. Thus we flre only negative weight nodes. This is repeated until no further flring of these nodes is possiple. Let the graph at this point be denoted as $G$. Note that in $G$ at each negatlve-welght node, there will be at least one edge with zero token, incident into the node.

Also we show that each negative-weight node $v_{i}$ would have been flred exactly $f_{i}$ times where $f_{i}$ is the token in $G^{\prime}$ of a shortest path to $v_{i}$ from a positlve welght node. So to avold redundant firings we compute in $G$ the value of $f_{i}$ 's for all the negative welght nodes and then fire the nodes accordingly. This will transform the graph $G$ to $G$. Note that this step involves only shortest path computations and can be done very efflciently using the distrlbuted/parallel algorithm presented in [10]. We shall call this as Algorithm SHORT-PATH.

Consider now the graph $G^{\prime \prime}$. A number of edge, tokens in $G^{\prime}$ will be zero. The subgraph of $G$ induced by the zero-token edges may not be connected. In that case, let the, connectted components of this subgraph be $G_{1}, G_{13}$, $\ldots, G_{k}$. We then construct the graph $G_{1,}^{\prime}$ as pollows. Node, $i$ in $G$ represents $G_{i}^{\prime}$ ' and the edge $e_{i j}$ (directed from node $i$ to node $j$ ) will be assigned the smallest of the tokens of all edges directed from $G_{i}$ to $G_{j}$.

Next we compute the weight of each node (which is now a cluster of nodes) in $G^{\prime}$ given by the sum of the welghts of all the nodes in the corresponding cluster. Then we apply algorithm SHORT-PATH to compute for each negativeweight node its shortest path from a positlve weight node and then flre these nodes by the approprlate amounts. Note that flring a cluster $x$ times results in adding $x$ to the current flring numbers of all the nodes in the cluster.

We repeat the above process untll all nodes coalesce into a single cluster. At this point we will have obtained a basic feasible solution (represented by a spanning tree) of the dual simplex. We now test the optimality of the solution using the simplex optimality criterion. Suppose the solution is not optimal. Then we determine for each branch $(i, j)$ of the spanning tree (representing the baslc solution) the corresponding fundamental cutset. Let the corresponding vertex partition be $\left(V_{i}\right.$, $\left.\bar{V}_{i}\right)$. Assume without loss of generallty that the node $i$ is in $V_{i}$. Then $V_{i}$ will be called the fundamental cluster corresponding to the branch $(i, j)$. If the weight of the cluster $V_{i}$ is negatlve then we could fire $V_{i}$ to decrease the value of the objectlve. Flring a fundamental cluster $V_{i}$ is in fact the same as a simplex plvot operation with respect to the branch $(i, j)$. Firing all negative welght fundamental clusters may result in producing negative tokens. So, we have deslgned a strategy to concurrently flre certain negative welght fundamental clusters in an approprlate manner so that no token will become negatlve during this process.

At the end of above steps, the solution may not be basic. In such case, we repeat the above process until an optimum basic feasible solution is obtalned.

Thus summarlzing, our approach consists of the following maln steps. We start with the given graph and the assoclated edge tokens prescribed by $M_{0}$. 
Step 1: We apply Algorithm FEASIBLE to test feasibillty of the problem. At the end of this step, all the edge tokens wlll be non-negatlve.

Step 2: We then flre negatlve welght nodes as much as possible with a vlew to decreasing the objectlve function. This process can be performed very efflclently using Algorlthm SHORT-PATH. When no more firings of negative welght nodes is possible, the nodes will partition into clusters. At this polnt, we flre negative welght clusters as much as posslble. Agaln, this can be done efficlently by constructing a smaller graph in which a node represents a cluster and then applying Algorithm SIORT-PATH on this new graph.

Step 3: We repeat step 2 until we obtain a baslc solution (represented by a spanning tree) of the dual simplex. At this point, we test the optimality of the solution using the simplex optimality criterion. If the solution is not optimal we flre concurrently in an appropriate manner negatlve welght fundamental clusters and decrease the value of the objective as much as possible.

At the end of Step 3, the solution may not be baslc. We now repeat steps 2 and 3 until optlmallty is reached.

The Interesting features of the above approach are:

1) No auxlliary graph is constructed to test feasibility.

11) Node and cluster flring operations of step $\mathbf{2}$ can be performed efflclently using Algorithm SHORT-PATH.

1ii) Several simplex pivot operations are performed concurrently in step 3 . The classical simplex approach does not permit concurrent pivots because these operations will destroy basicness of the solution.

Iv) If the solution at the end of step 3 is not basic, step 2 will convert it to a basic solution with an objectlve value less than that of the previous basic solution. In other words, step 2 converts a non-basic solution to a basic one wlthout ever increasing the value of the objective function.

This algorithm is now under implementation sultable for execution on the Hypercube computer. We are currently trying to port this -dual algorlthm to the Cosmic Envlronment and Reactlve Kernel systems (CE/RK) [11] which support a multl-process message passing environment. The CE/RK environment provides uniform communicatlon between processes Independent of their actual location. Since our algorlthm consists of a collectlon of processes which communicate with each other by passing messages it will be fairly easy to port this algorithm to the $\mathrm{CE} / \mathrm{RK}$ environment. We plan to study the run-time characteristics of the parallel algorithm under these conditions.

\section{SUMMARY}

In this paper we have presented the essential features of a parallel algorlthm for the layout compaction. Starting with a formulation (in terms of the dual transshipment problem) we have designed a parallel algorithm which in addition to shortestpath computations, involves concurrent pivot operations. This algorithm can also be used to study the relative placement problem studied in 7]. The parallel algorithm is now under implementation.

\section{REFERENCES}

[1] R.J. Brouwer and P. Banerjee, "A Parallel Simulated Annealing Algorithm for Channel Routing on a Hypercube Multiprocessor", Proc. Intl. Conf. on Computer Design, 1988, pp. 4-7.

[2] M.Y. Hseuh, "Symbolic Layout and Compaction of Integrated Circuits", U.C. Berkeley, UCB/ERL Report, M79/80, 1979.

[3] J.S. Rose, W.M. Snelgrove and Z.G. Vraneslc, "Parallel Standard Cell Placement Algorithms with Quality Equivalent to Simulated Annealing", IEEE Trans. CAD of ICAS, Mar. 1988, pp. 387-96.

[4] T. Yoshimura, "A Graph-Theoretic Compaction Algorithm", Proc. of ISCAS 85, 1985, pp. 1455-1458.

[5] K. Thulastraman and M.A. Comeau, "Maximum Weight Markings in Marked Graphs: Algorithms and Interpretations Based on the Simplex Method", IEEE Trans. on Circuits and Systems, Vol. CAS-34, Dec 1987, pp. 1535-1545.

[6] K. Thulastraman and M.A. Comeau, "Structure of the Submarking Reachability Problem and Network Programming", IEEE Trans. CAS, Jan 1988, pp. 89-100.

[7] B.X. Weiss and D.A. Mlynskl, "A GraphTheoretic Approach to the Relative Placement Problem", IEEE Trans. CAS, Vol. 35, March 1988, pp. 286-293.

[8] V. Chvátal, "Linear Programming," W.H. Freeman and Company, New York, 1983.

[9] M.A. Comeau, K. Thulasiraman and K.B. Lakshmanan, "An Efficient Asynchronous Distributed Protocol to test Feasibility of the Dual Transshipment Problem", Proc. 25th Allerton Conf. on Communication, Control and Computing, Sep. 1987, pp. 634-640.

[10] K.B. Lakshmanan, K. Thulasiraman and M. Comeau, " An Efficient Distributed Protocol for the Single Source Shortest Path Problem In Networks with Negative Weights", IEEE Trans, on Software Engineering, May 1989, pp. 639-644.

[11] C.L. Seltz, J. Selzovic and W.K. Su, "The $C$ Programmer's Abbreviated Guide to Multicomputer Programming", Caltech Computer Science Technical Report, Caltech-CS-TR88-1, Jan. 1988. 